\title{
Foliar release of soluble reactive phosphorus from Spartina alterniflora in a Georgia (USA) salt marsh
}

\author{
J. Dean Pakulski * \\ Department of Zoology and Institute of Ecology, University of Georgia, Athens, Georgia 30602, USA
}

\begin{abstract}
Foliar release of soluble reactive phosphorus (SRP) from live shoots of Spartina alterniflora (Loisel.) was investigated in a Georgia (USA) salt marsh. Average foliar SRP release rates varied from undetectable to $7.5 \mu \mathrm{g} \mathrm{P}$ (g dry $\mathrm{wt}^{-1} \mathrm{~h}^{-1}$ with values from individual plants as high as $61.7 \mu \mathrm{g} \mathrm{P}$ (g dry $w t)^{-1} h^{-1}$. Release rates of SRP generally exhibited little diel variation and were highest in midsummer. Estimates of extrafoliar SRP accumulated on leaf surfaces varied from $<1$ to $41 \mu \mathrm{g} \mathrm{P}\left(\mathrm{g}\right.$ dry wt leaf) ${ }^{-1}$ and 0.8 to $1.7 \mathrm{mg} \mathrm{P} \mathrm{m}^{-2}$ normalized to marsh area. Time course experiments revealed that SRP release was a 2 -step process with a rapid solubilization of extrafoliar SRP and a constant release thereafter. Releases of SRP from creekbank stands of $S$. alterniflora during tidal submergence were estimated to be 3.1 to $8.2 \mathrm{mg} \mathrm{P} \mathrm{m}^{-2} \mathrm{~d}^{-1}$, with annual releases of $1.7 \mathrm{~g} \mathrm{P} \mathrm{m}^{-2} \mathrm{yr}^{-1}$ Foliar releases of SRP from the live plants are equivalent to $60 \%$ of the annual production of particulate phosphorus as $S$. alterniflora detritus reported from Georgia salt marshes.
\end{abstract}

\section{INTRODUCTION}

The salt marshes of eastern North America have been shown to exchange soluble reactive phosphorus (SRP) with adjacent coastal waters during tidal inundation (Axelrad 1974, Heinle \& Flemer 1976, Woodwell \& Whitney 1977, Valiela et al. 1978, Jordan et al. 1983, Whiting et al. 1985, Dame et al. 1986, 1991). These marshes contain a variety of subsystems (oyster reefs, mussel beds, high and low marsh vegetation, marsh and subtidal sediments) each of which may act as a source or a sink for SRP during tidal exchange (Keunzler 1961, Gardner 1975, Wolaver et al. 1983, Dame et al. 1989). The relative contribution of each of these subsystems to the net tidal exchange of SRP from the marsh, however, is not fully understood (Nixon 1980, Wolaver et al. 1984).

While foliar uptake and release of SRP has been reported for a number of freshwater and marine macrophytes (McRoy et al. 1972, Twilley et al. 1977, Barko \& Smart 1980, Penhale \& Thayer 1980, Carignan \& Kalff

\footnotetext{
- Present address: Marine Science Institute, University of Texas at Austin, Port Aransas, Texas 78373, USA
}

1982, Brix \& Lyngby 1985) the evidence that Spartina alterniflora (Loisel.) acts as a 'phosphorus pump' (Nixon 1980) by transferring phosphorus from the sediment to the water column during tidal submergence has been equivocal. Reimold (1972) reported that $S$. alterniflora can assimilate, translocate, and release from its shoots ${ }^{32} \mathrm{P}$-orthophosphate injected into marsh sediments. Reimold's (1972) estimates of phosphorus release from the plants ( 90 to $164 \mu \mathrm{gP}$ (g wet $w)^{-1} \mathrm{~h}^{-1}$, $0.6 \mathrm{~g} \mathrm{P} \mathrm{m}^{2} \mathrm{~d}^{-1}$, however, may have overestimated actual release rates. Using data obtained from a number of East and Gulf coast (USA) marshes, Nixon (1980) estimated that 0.4 to $1.8 \mathrm{~g} \mathrm{P} \mathrm{m}^{-2} \mathrm{yr}^{-1}$ of phosphorus would have to be removed from salt marsh sediments in order to reconcile marsh soil phosphorus profiles with known rates of phosphorus deposition. From these estimates, Nixon (1980) concluded that unrealistically high rates of phosphorus deposition would be needed to balance marsh soil phosphorus budgets at phosphorus removal rates proposed by Reimold (1972).

In contrast to the high rates of phosphorus release reported by Reimold (1972), McGovern et al. (1979) reported extremely low rates of foliar SRP secretion [0.09 $\mu \mathrm{g} P(\mathrm{~g} \text { dry } w \mathrm{t})^{-1} \mathrm{~h}^{-1}$ ] from Spartina alterniflora main- 
tained in a greenhouse. McGovern et al. (1979) further concluded, on an annual basis, that foliar secretion of SRP by $S$. alterniflora was substantially less than atmospheric phosphorus deposition in New England (USA) marshes. The discrepancy between the conclusions of Reimold (1972) and McGovern et al. (1979) has never been resolved and foliar exchange of SRP by $S$. alterniflora has never been directly measured in the field. To resolve these questions, the foliar release of SRP from S. alterniflora was investigated in a Georgia salt marsh.

\section{MATERIALS AND METHODS}

Preparation of leaf incubation solutions. Foliar SRP exchange rates were estimated by incubating live leaves of Spartina alterniflora in sterile Whirl-Pac ${ }^{\mathrm{TM}}$ bags containing filtered creek water and detcrmining the differences in the concentrations of SRP between experimental (with leaves enclosed) and control (without leaves) bags (Gallagher et al. 1976, Pakulski 1986, Pakulski \& Kiene 1992).

Creek water used for incubation solutions was prefultered through a $0.22 \mu \mathrm{m}$ membrane/glass fiber filter assembly and subsequently filtered through a $0.10 \mu \mathrm{m}$ membrane (MSI Magna Nylon 66) enclosed in a separate Plexiglass holder. Filter holders were scrubbed with cleanroom wipes and a weak detergent solution, washed briefly with a solution of $\mathrm{NaOH}$-saturated methanol, and rinsed with copious quantities of Milli$Q$ deionized water before assembly. Assembled filter holders were flushed briefly with $1 \mathrm{~N} \mathrm{HCl}$ and immediately thereafter with copious quantities of Milli-Q water. The first $1000 \mathrm{ml}$ of filtrate was discarded at each step during filtration.

For each experiment, 20 Whirl-Pac bags were filled with $150 \mathrm{ml}$ of $0.1 \mu \mathrm{m}$ filtered water and were allowed to equilibrate to ambient creek water temperature in a bath. A Whirl-Pac bag containing filtered creek water and Spartina alterniflora leaves was used to estimate changes in experimental bag temperatures during incubations. Temperatures in incubating bags varied by an average of $\pm 2.8^{\circ} \mathrm{C}$ from initial temperatures during incubations. Salinities of creek water and incubation solutions were measured with an optical refractometer.

Sample collection. Plants were sampled over a 10 to $14 \mathrm{~d}$ period at 2 to 4 mo intervals at high tides occurring at dawn, midday, dusk, and midnight. Five plants were sampled at each high tide. The quantity of SRP accumulated on the leaves prior to sampling (hereafter referred to as extrafoliar accumulations) was estimated by incubating selected leaves for $60 \mathrm{~s}$ in a Whirl-Pac bag containing $150 \mathrm{ml}$ of $0.10 \mu \mathrm{m}$ filtered creek water. After the $60 \mathrm{~s}$ incubations, the leaves were removed from the bags. The leachate solutions were poisoned with sodium azide ( $20 \mathrm{mM}$ final concentration) and frozen immediately. The leaves were then gently cleaned with a cleanroom wipe and incubated for 120 min in a separate Whirl-Pac bag containing $150 \mathrm{ml}$ of $0.1 \mu \mathrm{m}$ filtered water.

Leaves remained attached to the plants during incubation. Only leaves from portions of plants exposed at high tide were used for incubation experiments. Incubating bags were supported on ring stands inserted into the sediment next to the plants and were not submerged at any time during the course of the incubations.

At the termination of the 120 min incubations, the incubated leaves were removed from the bags. The leachate solutions were poisoned immediately with sodium azide and frozen. The leaf material immersed in the incubation solutions was excised from the plant and dried for at least $7 \mathrm{~d}$ at $60^{\circ} \mathrm{C}$ for weight determinations.

Time zero and $120 \mathrm{~min}$ control bags containing 150 $\mathrm{ml}$ of $0.1 \mu \mathrm{m}$ filtered water were prepared for each plant. Time zero control solutions were poisoned with sodium azide and frozen immediately at the begining of the 120 min incubations. The 120 min control bags were poisoned and frozen upon termination of the incubations

Chemical analyses and calculations of foliar exchange rates. Soluble reactive phosphorus was determined by the molybdic acid reaction as outlined by Parsons et al. (1984). Foliar exchange rates were calculated only when there was a statistically significant difference $(p<0.05$, Student's $t$-test $)$ between the SRP concentration of the individual experimental bags and the 120 min controls. If there were no significant differences between the concentration of SRP in the experimental bags and the $120 \mathrm{~min}$ controls, the net exchange rate was determined to be zero. Mean exchange rates for each experiment were calculated from all plants sampled and include zero values. Quantities of extrafoliar SRP were calculated only when there was a significant difference $(p<0.05$, Student's $t$-test) between the SRP concentration of the $60 \mathrm{~s}$ incubation bags and the time zero controls. Since accumulation rates of extrafoliar SRP were not investigated, the contribution of solubilized extrafoliar SRP was not included in calculations of net SRP release from the plants

Time course of SRP release. The time course of SRP release from the plants was investigated by incubating leaves from duplicate sets of plants as described above for $1,30,60,90$ and 180 min intervals in Whirl-pac bags containing $150 \mathrm{ml}$ of freshly prepared $0.1 \mu \mathrm{m}$ filtered creek water. Samples from the 1 min incubations were obtained from unwiped leaves and were used to 
estimate the quantity of extrafoliar SRP present on the plants at the time of sampling. Samples from all other time intervals were obtained from leaves that were wiped clean with a cleanroom wipe and rinsed with $0.1 \mu \mathrm{m}$ filtered creek water. Duplicate time zero and final time control bags containing $150 \mathrm{ml}$ of freshly prepared $0.1 \mu \mathrm{m}$ filtered creek water were prepared for each set of plants. The release of SRP per time interval was calculated as the amount of SRP released from the wiped plants over each time interval plus the quantity of extrafoliar SRP present on the unwiped leaves estimated from the 1 min incubations.

Exchange of SRP by tidally deposited material. In Georgia salt marshes, substantial quantities of tidally deposited particulate material are present on Spartina alterniflora leaf surfaces in the summer months (Pakulski unpubl.). To examine the potential impact of tidally deposited material on the exchange of SRP from the plants, particulate material was collected by vigorously agitating 5 plants for $1 \mathrm{~min}$ in a flask containing $2500 \mathrm{ml}$ of freshly prepared $0.1 \mu \mathrm{m}$ filtered creek water. Aliquots $(100 \mathrm{ml})$ of the resulting suspension were dispensed to Whirl-pac bags. Two sets of suspensions in duplicate were prepared for each time point of the incubation. One set of suspensions was poisoned with sodium azide ( $40 \mathrm{mM}$ final concentration) and one remained unpoisoned. Incubation solution control bags containing $100 \mathrm{ml}$ aliquots of $0.1 \mu \mathrm{m}$ filtered creek water were also prepared. One set of live and poisoned controls in duplicate were prepared for each set of experimental bags. All experimental and control bags were incubated on a shaker in the dark at ambient creek water temperature $\left(31^{\circ} \mathrm{C}\right)$. Experimental and final time control bags were poisoned with sodium azide and frozen immediately at the end of incubation. The bags were thawed and the contents filtered through combusted glass fiber filters prior to analysis for SRP.

Determination of tidal exchange rates. Seasonal changes in the vertical distribution of Spartina alterni- flora leaf biomass and the duration of tidal submergence of leaf material were measured throughout the investigation in order to estimate the release of SRP from the creekbank zone of the marsh. A transect was established extending from the top of the natural levee to the edge of the vegetation zone in the creek. Stakes and twine were used to divide the vegetation along the transect into vertical sections $25 \mathrm{~cm}$ in depth. The length of time each vertical section was submerged was determined for a spring and neap tide at each sampling period. To estimate the vertical distribution of leaf biomass, leaf material was harvested for dry weight determination within each vertical section at 4 randomly selected $0.25 \mathrm{~m}^{2}$ plots along the transect.

Tidal exchange rates represent time-integrated SRP releases from the study site over entire tidal cycles. For each of the 4 plots along the transect, the release rate for each vertical section within each plot was calculated by multiplying the mean leaf weight-specific SRP release rate for that sampling period $(\mu \mathrm{g} \mathrm{P} \text { (g dry } w \mathrm{t})^{-1}$ $\mathrm{h}^{-1}$; mean of 4 dates within each sampling period] by the quantity of leaf biomass present ( $g$ dry wt) within that particular vertical section and the length of time (h) that section was submerged over the tidal cycle. The total release from each plot was calculated by summing the releases from all vertical sections within each plot. The flux from the creekbank area of the marsh was calculated as the mean exchange from the 4 plots along the transect. Daily rates were calculated assuming 2 high tides a day.

\section{RESULTS}

\section{SRP release rates and extrafoliar SRP accumulations}

Incubations ( $60 \mathrm{~s}$ and $2 \mathrm{~h}$ ) of leaf material typically resulted in a 10 to $45 \mu \mathrm{g} \mathrm{P1^{-1 }}$ increase in experimental bag SRP concentrations over those measured in control solutions (Table 1). Of the 99 comparisons between

Table 1 Spartina alterniflora. Soluble reactive phosphorus (SRP) concentrations, dry weights of incubated leaf material, extrafoliar SRP accumulations and foliar SRP release rates from dawn (06:00 to 08:00 h), August 10, 1988. TS-1 to 5 refer to data from individual plants. SRP concentrations = mean $\pm 1 \mathrm{SD}$. All SRP analyses were conducted in triplicate

\begin{tabular}{|c|c|c|c|c|c|c|c|}
\hline Plant & $\begin{array}{c}\text { Leaf } \\
\text { weight } \\
\text { (g dry wt) }\end{array}$ & $\begin{array}{l}\text { Time zero } \\
\text { control } \\
\text { SRP conc } \\
\left(\mu g \mathrm{Pl}^{-1}\right)\end{array}$ & $\begin{array}{l}60 \text { s incubation } \\
\text { SRP conc. } \\
\left(\mu g \mathrm{P}^{-1}\right)\end{array}$ & $\begin{array}{c}\text { Extrafoliar } \\
\text { SRP } \\
\text { accumulation } \\
{\left[\mu \mathrm{g} P(\mathrm{~g} d r y \text { wt })^{-1}\right]}\end{array}$ & $\begin{array}{l}120 \text { min control } \\
\text { SRP conc. } \\
\left(\mu \mathrm{g} \mathrm{P} \mathrm{l}^{-1}\right)\end{array}$ & $\begin{array}{l}120 \text { min } \\
\text { incubation } \\
\text { SRP conc. } \\
\left(\mu \mathrm{P} \mathrm{I}^{-1}\right)\end{array}$ & $\begin{array}{c}\text { Foliar SRP } \\
\text { release rate } \\
{\left[\mu \mathrm{g} \mathrm{P}(\mathrm{g} \text { dry } w \mathrm{t})^{-1} \mathrm{~h}^{-1}\right]}\end{array}$ \\
\hline TS-1 & 0.30 & $134.2 \pm 3.7$ & $153.1 \pm 1.9$ & 9.5 & $140.1 \pm 0.9$ & $184.1 \pm 1.0$ & 11.0 \\
\hline TS-2 & 0.31 & $138.0 \pm 1.9$ & $151.0 \pm 3.1$ & 6.3 & $139.2 \pm 0.9$ & $160.3 \pm 3.3$ & 5.1 \\
\hline TS-3 & 0.12 & $135.8 \pm 1.6$ & $155.0 \pm 2.5$ & 24.0 & $139.8 \pm 0.1$ & $146.0 \pm 0.1$ & 3.9 \\
\hline TS-4 & 0.46 & $139.8 \pm 1.6$ & $161.5 \pm 3.1$ & 7.1 & $137.3 \pm 1.9$ & $155.9 \pm 0.9$ & 3.1 \\
\hline TS-5 & 0.31 & $140.1 \pm 0.9$ & $154.4 \pm 2.2$ & 6.9 & $140.1 \pm 1.0$ & $169.0 \pm 2.2$ & 7.0 \\
\hline
\end{tabular}



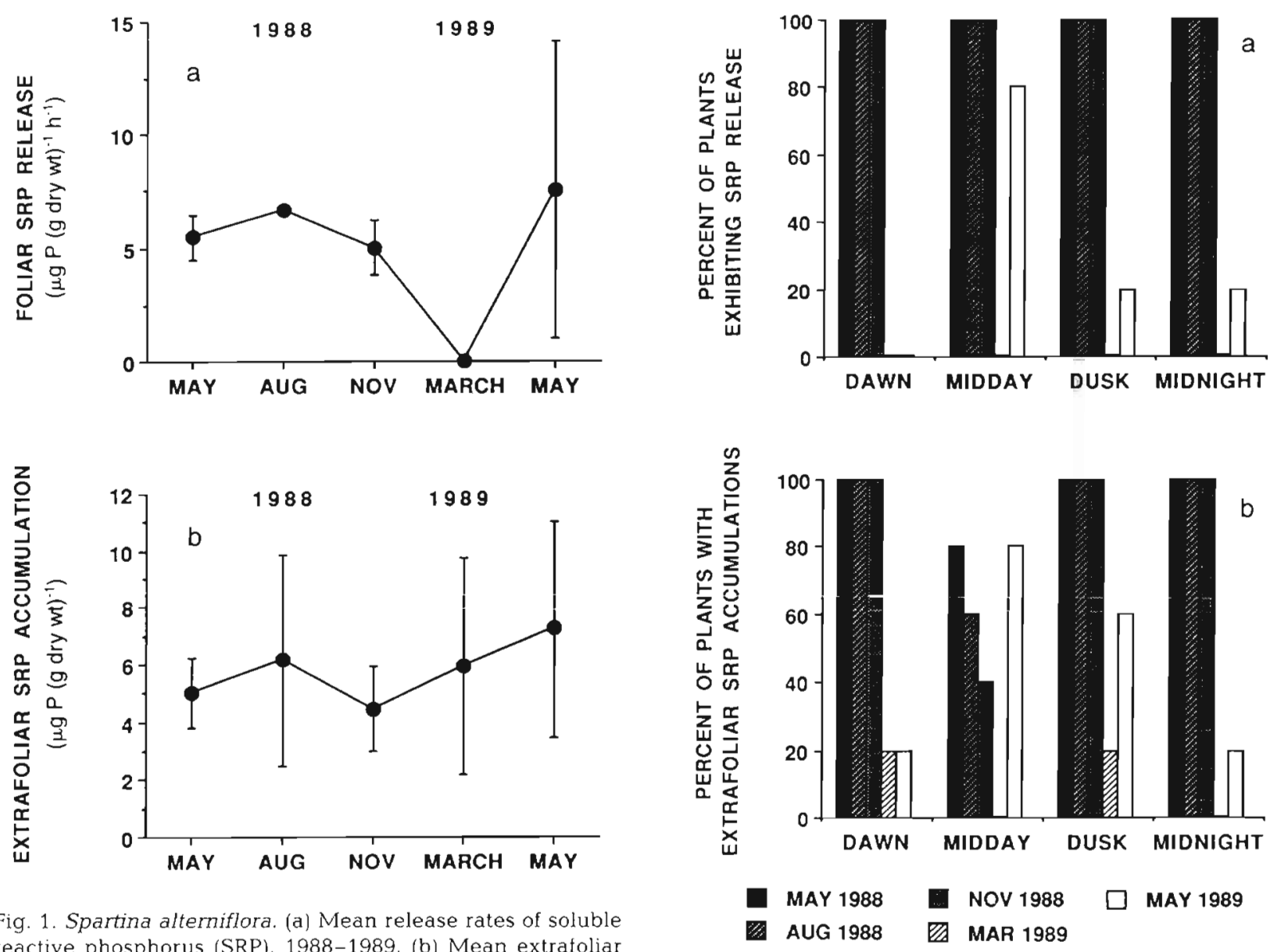
reactive phosphorus (SRP), 1988-1989. (b) Mean extrafoliar accumulations of SRP on S. alterniflora. Each point represents the mean ( $\pm 1 \mathrm{SE}$ ) from 4 sampling dates

$t=0$ and $t=120$ min control solutions, 87 exhibited no statistically significant change in SRP concentration. In the remaining experiments, statistically significant increases or decreases in control solution SRP concentrations were small and averaged $\pm 4.5 \mu \mathrm{g} \mathrm{P} \mathrm{l^{-1 }}$ over the $2 \mathrm{~h}$ incubations. No net uptake of SRP by the plants was observed at any time during the investigation.

Mean foliar release rates of SRP (mean of 4 dates within each sampling period) varied from <0.1 to 7.5 $\mu g \mathrm{P}(\mathrm{g} \text { dry } w \mathrm{t})^{-1} \mathrm{~h}^{-1}$ (Fig. 1a). Foliar release rates from individual plants were as high as $61.7 \mu \mathrm{g} \mathrm{P}(\mathrm{g} \text { dry } w \mathrm{t})^{-1}$ $\mathrm{h}^{-1}$. Highest mean release rates were recorded in August 1988 and May 1989. There was no detectable release of SRP from the plants during March 1989. Strong diel variation in SRP release rates in May 1989 (discussed below) contributed to the high variance in the mean release rate recorded for that period.

Extrafoliar SRP was present on leaf surfaces throughout the year with mean values (mean of 4 dates within each sampling period) ranging from 5.1 to $7.2 \mu \mathrm{g} P(g \text { dry } w t)^{-1}$ (Fig 1b). Extrafoliar SRP accumulated on individual plants ranged from undetectable to

Fig. 2. Spartina alterniflora. Percentage of plants (a) exhibiting soluble reactive phosphorus (SRP) release, 1988-1989 and (b) with extrafoliar accumulations of SRP, 1988-1989. Each bar represents the percentage of plants exhibiting SRP release or accumulations from 5 plants sampled at each date

$41 \mu \mathrm{g} \mathrm{P}\left(\mathrm{g}\right.$ dry $w \mathrm{t}^{-1}$. Unlike SRP release rates, there appeared to be no seasonal trend in extrafoliar SRP accumulations. There was a weak but significant correlation ( $p=0.01, r=0.39, n=99$ ) between extrafoliar SRP accumulations on individual leaves and SRP release rates.

During $1988,100 \%$ of the plants sampled exhibited net release of SRP (Fig, 2a). There were no statistically significant releases of SRP from the plants sampled in March 1989. A smaller percentage (mean $=30 \%$ ) of the plants exhibited SRP release during May 1989 than during the same period in 1988. During 1988, extrafoliar SRP was present on $100 \%$ of the plants, while extrafoliar SRP was present on less than $30 \%$ of the plants during 1989 (Fig. 2b). In May 1989, a higher percentage of plants exhibited SRP release and extrafoliar accumulations during midday than in the morning or evening hours. 

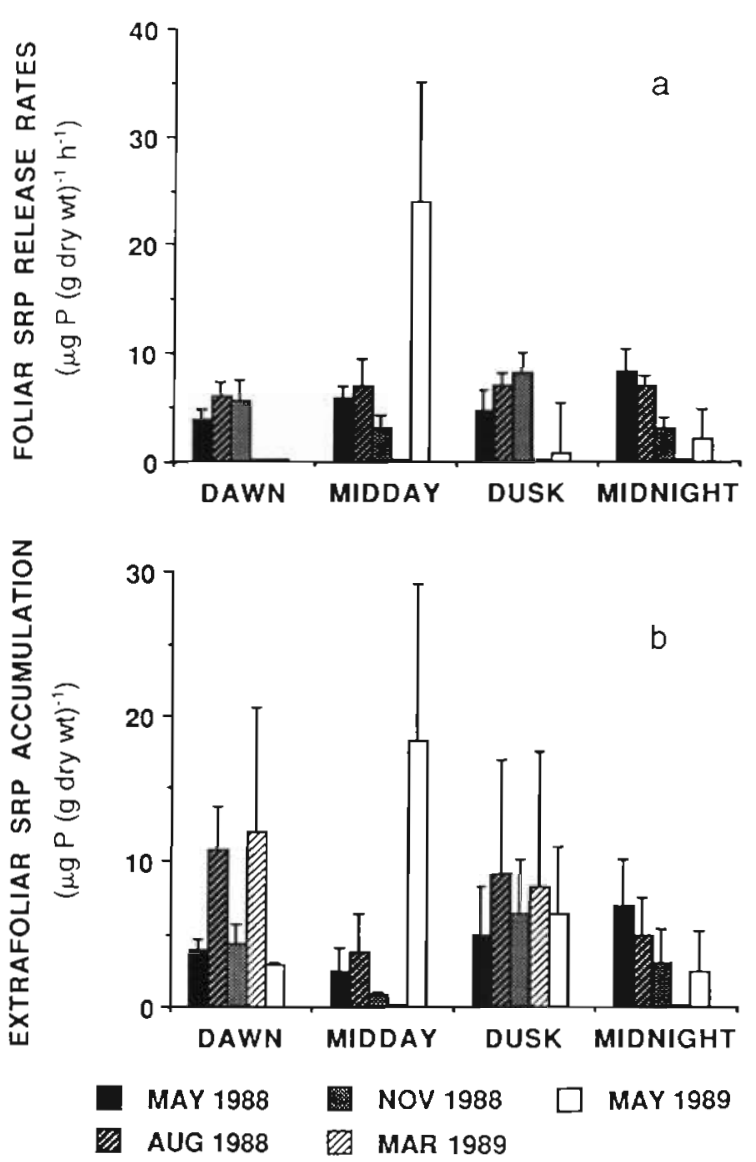

Fig. 3. Spartina alterniflora. Diel variation of (a) release of soluble reactive phosphorus (SRP) from live leaves from Sapelo Island, Georgia, and (b) soluble reactive phosphorus (SRP) accumulations on leaves. Each bar represents the mean ( \pm 1 SE) from 5 plants

\section{Diel variation in foliar SRP release rates and extrafoliar accumulations}

Foliar release rates were remarkably similar between sampling dates and exhibited little diel variation during the entire 1988 sampling period (Fig. 3a). No release was detected at any time during March 1989. Release rates during May 1989, however, were undetectable in the morning hours, highest in the middle portion of the day and declined into the evening hours (Fig. 4a). Extrafoliar SRP accumulations exhibited no strong diel trends during 1988 (Fig. 3b). However, in May 1989 extrafoliar SRP exhibited a pattern similar to the trend in SRP release rates observed during the same period. This was the only period during the investigation where diel trends in SRP release or accumulations were observed.

\section{Time course studies}

The release of SRP from Spartina alterniflora leaves appeared to be a 2 -step process with an initial rapid
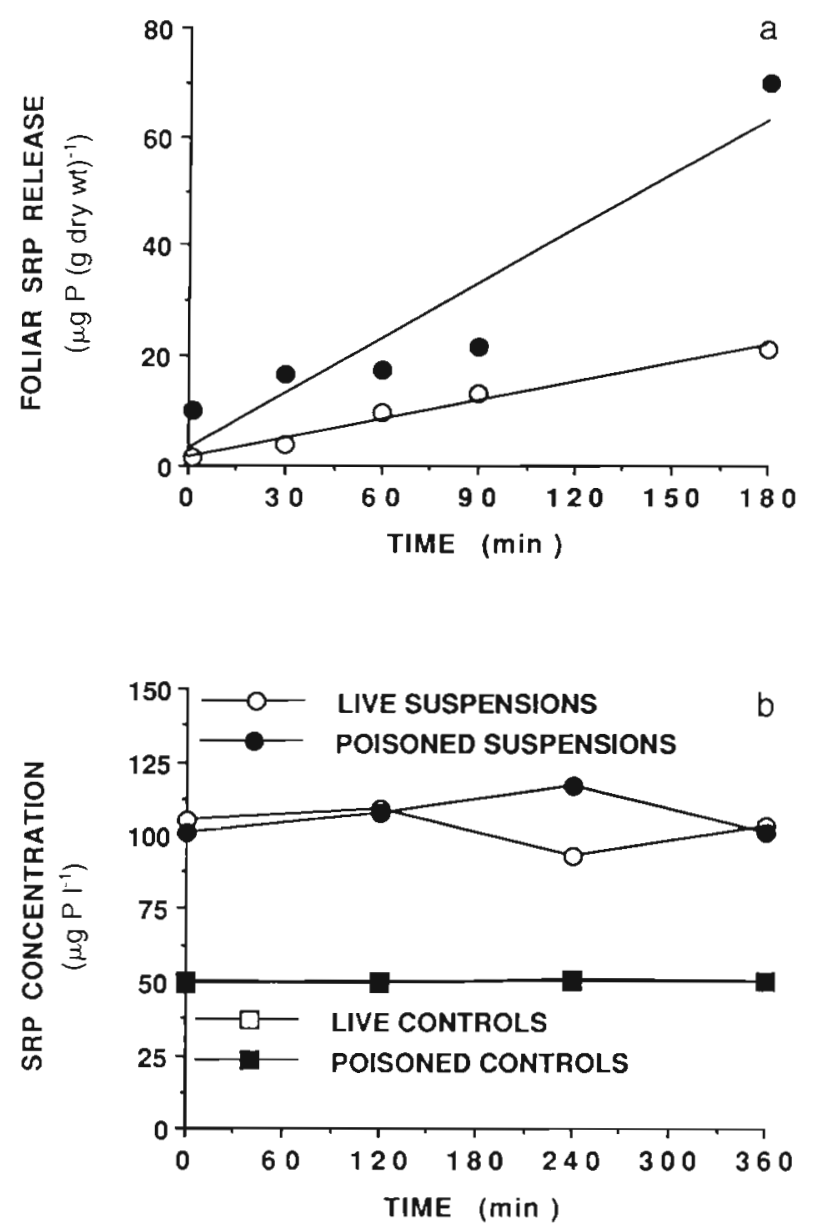

Fig. 4. Spartina alterniflora. (a) Time course of soluble reactive phosphorus (SRP) release, May (O) and August (O) 1988. Each point represents the mean quantity of SRP released per g dry wt of leaf from 2 plants over each incubation interval plus the quantity of extrafoliar SRP present on the leaves estimated from the 1 min incubations. (b) Net SRP exchange associated with tidally deposited particulate material and microflora removed from S. alternifiora, August 1988. Each point represents the mean concentration of SRP from duplicate Whirl-Pac bags

solubilization of extrafoliar SRP and a constant release thereafter from leaf tissues (Fig 4a). The August 1988 time course experiment was conducted the day after a period of heavy rainfall. Extrafoliar accumulations recorded during the August 1988 experiment were lower than those typically recorded during the rest of the year presumably because much of this material had been removed by rainfall the previous day.

\section{SRP exchange from leaf particulate material}

Concentrations of SRP in bags containing suspensions of leaf particulate material were 2-fold higher than those present in the controls due to the removal of 
extrafoliar SRP from the leaves during sample collection. There was no apparent change in the concentrations of SRP in either the control or the experimental bags, indicating there was no net exchange of SRP from tidally deposited particulate material or loosely attached epiphytic organisms over the $6 \mathrm{~h}$ incubation period (Fig. 4b).

\section{Relationships between SRP release and environmental factors}

Mean creek water SRP concentrations varied from 53.8 to $115.6 \mu \mathrm{g} \mathrm{P}^{-1}$ with the highest creek SRP concentrations occurring in August 1988 and the lowest concentrations occurring in March 1989 (Table 2). Mean creek water salinities and temperatures varied from 27 to $32 \%$ and 16 to $32{ }^{\circ} \mathrm{C}$, respectively, with seasonal peaks in both paramelers occurring in August 1988 (Table 2). Regression analyses revealed significant relationships between foliar SRP release rates and creek water temperature $\left(r^{2}=0.36, p=0.005\right)$, salinity $\left(r^{2}=0.31, p=0.01\right)$, and creek water SRP concentrations $\left(\mathrm{r}^{2}=0.29, \mathrm{p}=0.01\right)$. Mean creek water SRP concentrations varied from 53 to $115 \mu \mathrm{g} \mathrm{P} ~^{-1}$ (Table 2) and yielded a significant regression with temperature $\left(\mathrm{r}^{2}=\right.$ $0.68, \mathrm{p}=0.01)$ but not salinity $\left(\mathrm{r}^{2}=0.18, \mathrm{p}=0.61\right)$.

\section{Tidal exchange of SRP}

Tidal releases of SRP from the creekbank area of the marsh varied little throughout the growing season, ranging from 3.1 to 4.3 and 7.3 to $8.2 \mathrm{mg} \mathrm{P} \mathrm{m}^{-2} \mathrm{~d}^{-1} \mathrm{du}$ ring neap and spring tides, respectively (Fig. 5). The higher releases calculated for spring tides reflected the increase in duration of tidal flooding and amount of leaf biomass submerged during these events. Annual foliar release of SRP from plants at the study site was estimated to be $1.7 \mathrm{~g} \mathrm{P} \mathrm{m}^{-2} \mathrm{yr}^{-1}$. Estimates of foliar accumulations of SRP normalized to marsh area varied

Table 2. Creek water salinities, temperatures and soluble reactive phosphorus concentrations recorded from South End Creek, May 1988 to May 1989. Values represent the mean $\pm \mathrm{SD}$ from the 4 sampling dates within each month

\begin{tabular}{|lccr|}
\hline Date & $\begin{array}{c}\text { Temperature } \\
\left({ }^{\circ} \mathrm{C}\right)\end{array}$ & $\begin{array}{c}\text { Salinity } \\
(\%)\end{array}$ & \multicolumn{1}{c|}{$\begin{array}{c}\text { SRP } \\
\left(\mu \mathrm{gP}^{-1}\right)\end{array}$} \\
\hline May 1988 & $27 \pm 2$ & $28 \pm 2$ & $88.9 \pm 11.5$ \\
Aug 1988 & $32 \pm 2$ & $33 \pm 1$ & $115.6 \pm 32.4$ \\
Nov 1988 & $19 \pm 1$ & $29 \pm 1$ & $82.8 \pm 12.7$ \\
Mar 1989 & $16 \pm 3$ & $27 \pm 4$ & $53.8 \pm 19.1$ \\
May 1989 & $25 \pm 1$ & $27 \pm 1$ & $90.6 \pm 35.9$ \\
\hline
\end{tabular}

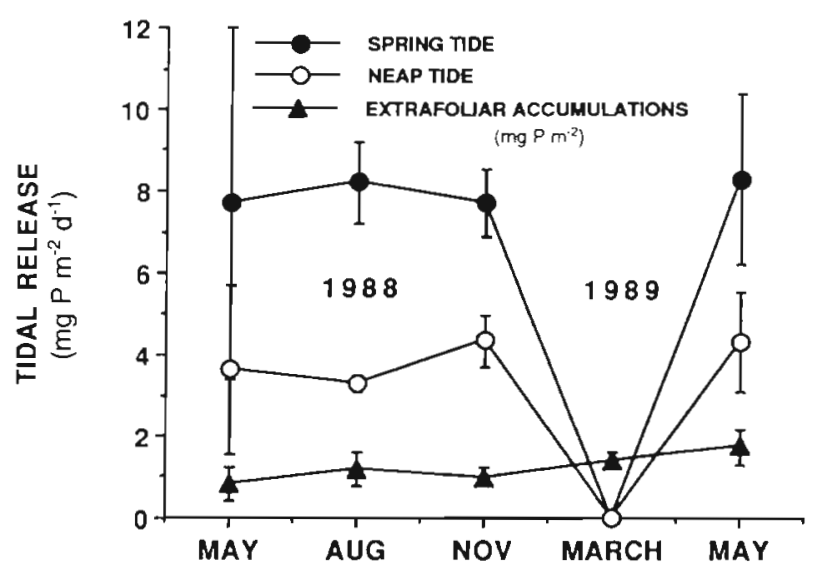

Fig. 5. Spartina alterniflora. Tidal releases and area normalized extrafoliar accumulations of soluble reactive phosphorus (SRP) from creekbank plants from Sapelo Island, Georgia. Each point represents the mean ( $\pm 1 \mathrm{SE}$ ) of 4 plots

from 0.8 to $1.7 \mathrm{mg} \mathrm{P} \mathrm{m}^{-2}$ throughout the investigation (Fig. 5). Potential losses of extrafoliar SRP were not used to calculate annual releases from the marsh.

\section{DISCUSSION}

\section{Tidal exchange of SRP from Spartina alterniflora}

Foliar releases of SRP from Spartina alterniflora appear to be an important flux of phosphorus in Georgia salt marshes. Nixon (1980) estimated that 0.4 to $1.8 \mathrm{~g} \mathrm{P}$ $\mathrm{m}^{-2} \mathrm{yr}^{-1}$ would have to be removed from East and Gulf coast salt marsh sediments to reconcile phosphorus sedimentation rates with marsh soil phosphorus concentration profiles. Tidal exchanges of orthophosphate between southeastern U.S. salt marsh-estuaries and coastal waters vary from an import of $0.2 \mathrm{~g} \mathrm{P} \mathrm{m}^{-2}$ $\mathrm{yr}^{-1}$ (Wolaver et al. 1983) to exports of $1.6 \mathrm{~g} \mathrm{P} \mathrm{m}^{-2} \mathrm{yr}^{-1}$ (Dame et al. 1986). Annual foliar releases of SRP from creekbank stands of $S$. alterniflora reported here $1.7 \mathrm{~g}$ $\mathrm{P} \mathrm{m}^{-2} \mathrm{yr}^{-1}$ ) are consistent with Nixon's (1980) estimates of soil phosphorus removal rates and also with estimates of SRP export (where it occurs) from salt marshes to adjacent waters.

Foliar releases of SRP were equivalent to a significant fraction of the $\mathrm{P}$ released from the mineralization of Spartina alterniflora detritus in Georgia salt marshes. Annual tidal releases of SRP from the present study were equivalent to $61 \%$ of the particulate phosphorus produced annually as detritus within the tall $S$. alterniflora zone of Georgia marshes $\left(2.8 \mathrm{~g} \mathrm{P} \mathrm{m}^{-2}\right.$ $\mathrm{yr}^{-1}$; Gallagher et al. 1980). Whitney et al. (1981) have further estimated that half the annual aerial production of $S$. alterniflora in Georgia salt marshes is mineralized 
in the marsh releasing $3 \mathrm{~g} \mathrm{P} \mathrm{m}^{-2} \mathrm{yr}^{-1}$. Annual foliar releases of SRP from the present study were equivalent to $57 \%$ of the annual P flux from the mineralization of $S$. alterniflora detritus reported by Whitney et al. (1981).

\section{Foliar release rates}

Estimates of foliar SRP release rates from Spartina alterniflora from the present study were at least an order of magnitude lower than those reported by Reimold (1972). In retrospect, it is unclear how Reimold calculated his estimates of $P$ release from the plants. The differences between Reimold's (1972) estimates of P release and those reported from the present study may be due to the assumptions used by Reimold to calculate $P$ fluxes from the plants and the marsh (e.g. see Whitney et al. 1981). Estimates of SRP losses from $S$. alterniflora from the present study, however, were 2 orders of magnitude greater than those reported by McGovern et al. (1979). The plants used by McGovern et al. (1979) were grown under greenhouse conditions and were not subjected to tidal immersion. Differences in the physiology of plants maintained under artificial conditions and plants sampled in situ may, in part, account for the differences in SRP release rates reported by McGovern et al. (1979) and those observed in the present study.

\section{SRP exchange from tidally deposited particulate material}

There was no net exchange of SRP from particulate material removed from Spartina alterniflora leaf surfaces. Particulate material and any microflora associated with leaf surfaces may not, therefore, significantly influence the release of SRP from the plants. SEM examination of live S. alterniflora leaves collected in late summer 1986 further revealed that the live plants were host to a remarkably sparse epiphyte community (Pakulski \& Kiene 1992). The above evidence, in conjunction with the results of Reimold's (1972) tracer experiments, suggests quite strongly that SRP was released from the plants themselves and not from epiphytes or particulate material associated with the leaves.

\section{Mechanisms of SRP release}

Reimold's (1972) tracer experiments clearly demonstrated that Spartina alterniflora behaves as a 'phosphorus pump' by removing phosphorus from the sedi- ment and releasing it from the shoots. Data from Reimold (1972) and the present study, however, revealed little that suggested any possible mechanism(s) by which SRP is released from the plants. The lack of any significant diel variation in SRP release rates during 1988 and the strong trend toward high daylight release rates during May 1989 make it difficult to relate these trends simply to daily variations in photosynthetic activity. The absence of detectable SRP release in March 1989 and the high release rates observed during the late spring and summer months, however, suggests some relationship between SRP release and shoot production.

The percentage of plants exhibiting foliar SRP release declined from $100 \%$ in May 1988 to $30 \%$ in May 1989. In addition, there were no discernable diel trends in foliar SRP releases in May 1988 and a pattern of high release rates during the midday hours in May 1989. It is not clear whether these differences in the pattern of SRP release were the result of changes in environmental conditions between the 2 growing seasons. The 1988-1989 sampling period was characterized by drought and higher than normal creek water salinities and temperatures. While there was a significant correlation between creek water salinities and SRP release rates, mean creek water salinities and temperatures did not differ appreciably between May 1988 and May 1989. Interannual variation in these 2 factors do not appear to adequately explain the differences in patterns of foliar SRP release between the 2 years. The results of the present investigation suggest that foliar release of SRP from Spartina alterniflora may involve interactions between physiological processes and environmental factors. Physiological mechanisms for foliar SRP release may involve the secretion of ions from leaf salt glands or the accumulation and subsequent leaching of salts from leaf surfaces and tissues as the result of transpiration. Environmental factors such as interannual variations in soil pore water chemistry or leaf tissue damage by phytophagous insects (Pfeiffer \& Wiegert 1981) may in turn modify the physiology of SRP release. The identification of these or other potential mechanisms, however, could not be determined from the data presented here.

\section{CONCLUSIONS}

The results of the present investigation agree with the observations of Reimold (1972) and strongly suggest that Spartina alterniflora behaves as a 'phosphorus pump' in Georgia salt marshes by mobilizing phosphorus from marsh soils and releasing SRP via the leaves during tidal inundation. Release rates of SRP from the plants in the present study, however, were at 
least an order of magnitude lower than those originally reported by Reimold (1972) and were consistent with the marsh soil $P$ budgets proposed by Nixon (1980). Foliar release of SRP from S. alterniflora appears to be an important flux of phosphorus within the marsh and may rival the amount of phosphorus released each year from the aboveground mineralization of $S$. alterniflora detritus in Georgia salt marshes.

Acknowledgements. The author thanks L. R. Pomeroy, W. Wiebe, J. Alberts, M. Darley and the staff of the University of Georgia Marine Science Institute for their support during this investigation. This work was supported by National Science Foundation doctoral dissertation improvement grant OCE 8514540 to L. R. Pomeroy and J.D.P.

\section{LITERATURE CITED}

Axelrad, D. M. (1974). Nutrient flux through the salt marsh ecosystem. Ph.D. thesis, Cullege of William and Mary

Barko, J. W., Smart, R. M. (1980). Mobilization of sediment phosphorus by submerged freshwater macrophytes. Freshwat. Biol. 10: 229-238

Brix, H., Lygnby, J. E. (1985). Uptake and translocation of phosphorus in eelgrass (Zostera marina). Mar. Biol. 90: $111-116$

Carignan, R., Kalff, J. (1982). Phosphorus release by submerged macrophytes: significance to epiphyton and phytoplankton. Limnol. Oceanogr. 27: 419-427

Dame, R., Chzranowski, T., Bildstein, K., Kjerfver, B., McKellar, H., Nelson, D., Spurrier, J., Stancyk, S., Stevenson, H., Vernberg, J., Zingmark, R. (1986). The outwelling hypothesis and North Inlet, South Carolina. Mar. Ecol. Prog. Ser. 33: 217-229

Dame, R., Spurrier, J. D., Wolaver, T. G. (1989). Carbon, nitrogen and phosphorus processing by an oyster reef. Mar. Ecol. Prog. Ser. 54: 249-256

Dame, R., Spurrier, J. D., Williams, T M., Kjerfver, B.. Zingmark, R., Wolaver, T. J., Chzranowski, T., McKellar, H. N., Vernberg, F. J. (1991). Annual material processing by a salt marsh-estuarine basin in South Carolina, USA. Mar. Ecol. Prog. Ser. 72: 153-166

Gallagher, J. L., Reimold, R. Linthurst, R., A., Pfeiffer, W. J. (1980). Aerial production, mortality, and mineral dynamics in Spartina alterniflora and Juncus roemerianus plant stands in a Georgia salt marsh. Ecology 61: 303-312

Gallagher, J. L., Pomeroy, L. R., Pfeiffer, W J. (1976). Leaching and microbial utilization of dissolved organic carbon from leaves of Spartina alterniflora. Estuar. coast Shelf Sci. 4: $467-4471$

Gardner, L. R. (1975). Runoff from an intertidal marsh during tidal exposure - recession curves and chemical characteristıcs. Limnol. Oceanogr. 20: 81-89

Heinle, D. R., Flemer, D. A. (1976). Flows of materials between a poorly flooded tidal marshes and an estuary. Mar. Biol. 35: 359-373

Jordan, T E., Correll, D. L., Whigham, D. F. (1983). Nutrient flux in the Rhode River: tidal exchange of nutrients by brackish marshes. Estuar. coast. Shelf Sci. 17: 651-667

Kuenzler, E. J. (1961). Phosphorus budget of a mussel population. Limnol. Oceanogr. 6: 400-415

This article was submitted to the editor
Lord, C. J. (1980). The chemistry of iron, manganese, and sulfur in salt marsh sediments. Ph.D. thesis, Univ. of Delaware

McRoy, C. P., Barstate, R. J., Nebert, M. (1972). Phosphorus cycling in an eelgrass (Zostera marina) ecosystem. Limnol. Oceanogr. 17: 58-67

McGovern, T A, Laber, L. J., Gram, B. C. (1979). Characteristics of the salts secreted by Spartina alterniflora Loisel. and their relation to estuarine production. Estuar. coast. Shelf Sci. 9: 351-356

Nixon, S. W. (1980). Between marshes and estuaries - a review of twenty years of speculation and research on the role of salt marshes in estuarine productivity and water chemistry. In: MacDonald, K. B., Hamilton, B. (eds.) Estuarine and wetland processes. Plenum Press, New York, p. 437-526

Pakulski, J. D. (1986). The release of reducing sugars and dissolved organic carbon from Spartina alterniflora Loisel. in a Georgia salt marsh. Estuar. coast. Shelf Sci. 22: 385-394

Pakulski, J. D., Kiene, R. P. (1992). Foliar release of dimethylsulfonioproprionate from Spartina alterniflora. Mar. Ecol. Prog. Ser. 81:277-287

Parsons, T. R., Maita, Y., Lallj, C. M. (1984). A manual of chemical and biological methods of seawater analysis. Pergamon Press, New York

Penhale, P. A., Thayer, G. W. (1980). Uptake and transfer of carbon and phosphorus by eelgrass (Zostera marina L.) and its epiphytes. J. exp. mar. Biol. Ecol. 42: 113-123

Pfeiffer, W., Wiegert, R. G. (1981). Grazers on Spartina and their predators. In: Pomeroy, L. R., Wiegert, R. G. (eds.) Ecology of a salt marsh. Springer-Verlag, New York, p. $91-92$

Reimold, R. J. (1972). The movement of phosphorus through the marsh cordgrass Spartina alterniflora Loisel. Limnol. Oceanogr. 17: 606-611

Twilley, R. R., Brinson, M. M., Davis, G. J. (1977). Phosphorus absorption, translocation, and secretion in Nuphar luteum. Limnol. Oceanogr. 22: 1022-1032

Valiela, I., Teal, J. M., Volkman, S., Shafe, D., Carpenter, E. J. (1978). Nutrient and particulate fluxes in salt marsh ecosystems: tidal exchanges and inputs by precipitation and groundwater. Limnol. Oceanogr. 23: 798-812

Whiting, G. J., McKellar, H. N., Kjerfve, B., Spurrier, J. D. (1985). Sampling and computational design of nutrient flux from a southeastern U.S. salt marsh. Estuar. coast. Shelf Sci. 21. 273-286

Whitney, D. M., Chalmers, A. G., Haines, E. B., Hanson, R. B., Pomeroy, L. R., Sherr, B. (1981). Cycles of nitrogen and phosphorus. In: Pomeroy, L. R., Wiegert, R. G. (eds.) Ecology of a salt marsh. Springer-Verlag. New York, p. $163-168$

Wolaver, T. G., Zieman, J. C., Wetzel, R., Webb, K. (1983). Tidal exchange of nitrogen and phosphorus between a mesohaline vegetated marsh and the surrounding estuary in the lower Chesapeake Bay. Estuar. coast. Shelf Sci. 16: $321-332$

Wolaver, T G., Johnson, W., Moarozas, M. (1984). Nitrogen and phosphorus concentrations within North Inlet. South Carolina - speculation as to sources and sinks. Estuar. Coast. Shelf Sci. 19: 243-255

Woodwell, G. M., Whitney, D. E. (1977). Flax Pond ecosystem study: exchanges of phosphorus between a salt marsh and the coastal waters of Long Island Sound. Mar. Biol. 41:1-6

Manuscript first received: April 7, 1992

Revised version accepted: November 10,1992 